\title{
Fuchs's heterochromic cyclitis and posterior capsulotomy
}

\author{
THOMAS J ROUSSEL AND DOUGLAS J COSTER \\ From the Department of Ophthalmology, Flinders Medical Centre, Bedford Park, South Australia 5042
}

SUMMARY We report a case of intractable glaucoma following an uncomplicated secondary posterior capsulotomy in a 48-year-old male with Fuchs's heterochromic cyclitis. The patient had been free of inflammation and glaucoma since cataract extraction 27 years previously. We also report the results of phenotypic analysis of lymphocytes removed from the anterior chamber.

The prognosis for successful intraocular procedures in eyes with Fuchs's heterochromic cyclitis has been variously reported. Franceschetti stated that the prognosis for cataract extraction in complicated heterochromia is excellent, perhaps even better than in normal eyes.' Smith and O'Connor reported minimal complications in 29 lens extractions in patients with Fuchs's syndrome. ${ }^{2}$ Conversely, Ward and Hart considered secondary glaucoma to be the most serious and most common condition associated with cataract extraction in this entity. ${ }^{3}$ Norn reported postoperative glaucoma in seven of $19(36 \%)$ patients undergoing cataract extraction for Fuchs's syndrome, ${ }^{4}$ and Huber described an abrupt rise in intraocular pressure following anterior chamber puncture in patients with this syndrome. ${ }^{5}$

We describe a protracted rise in intraocular pressure following posterior capsulotomy in an eye with Fuchs's syndrome. The eye had been free of inflammation for 27 years after extracapsular cataract surgery. The glaucoma was relentless and progressive despite medical and surgical management. We report this case to remind clinicians of the postoperative difficulties which can be encountered with this disease, to point out that posterior capsulotomy may not always be a trivial procedure in such cases, and to report a technique for studying the immunocytology of inflammatory cells in the anterior chamber.

\section{Case report}

A 48-year-old white male reported to Flinders Medical Centre Eye Clinic on 5 April 1983 with a

Correspondence to Dr T J Roussel. complaint of poor visual acuity in the right eye. A right extracapsular lens extraction had been done in that eye 27 years previously. Although there was good corrected vision at that time, his right visual acuity had decreased over several years prior to 1983 . There had been no episodes of intraocular inflammation or raised pressure since the time of cataract extraction.

Visual acuity was $6 / 60$ in the right eye and $6 / 5$ in the left eye. There was mild heterochromia, the right iris being lighter. The right cornea was clear except for a few fine, white endothelial deposits, and there were no signs of intraocular inflammation. The posterior capsule was moderately opacified, and there were multiple condensations in the right anterior vitreous. Iris transillumination defects were noted in the right eye, and its iris vasculature was clearly visualised owing to atrophic changes of the iris stroma. Intraocular pressure was $12 \mathrm{mmHg}$ by applanation, and the retinal examination was unremarkable. The left eye was normal.

On 9 May 1983 we performed an uncomplicated posterior capsulotomy through a clear corneal incision near the limbus. A trickle of blood, which appeared to originate from the angle opposite the site of entry, was noted during the procedure.

On the first postoperative day there was diffuse microcystic oedema of the corneal epithelium, a moderate aqueous inflammatory response, and a small hyphaema. Intraocular pressure by applanation was $60 \mathrm{mmHg}$. The raised pressure responded initially to acetazolamide, timolol, and atropine, so that on the following day the intraocular pressure was $20 \mathrm{mmHg}$, but still with moderate inflammatory signs in the aqueous.

A diagnostic anterior chamber paracentesis was 
performed in an attempt to establish whether the inflammation was a response to previously sequestered lens remnants or to reactivation of the underlying disease. The patient was then started on dexamethasone phosphate $0.1 \%$ four times daily in addition to the acetazolamide and timolol. Signs of intraocular inflammation remained unchanged on this regimen, but the intraocular pressure slowly rose, so that by the tenth postoperative day it was consistently between 30 and $40 \mathrm{mmHg}$, and by the twentieth day it was fluctuating between 40 and 45 $\mathrm{mmHg}$. At this point the patient developed acetazolamide intolerance, and the drug was discontinued. The topical steroid was increased to one drop every two hours for 10 days, then discontinued because it had no effect on the inflammatory signs and so as to eliminate the prospect of steroid responsiveness.

Because of progressive optic nerve head cupping and deterioration of the visual field, a trabeculectomy was performed on 5 September 1983. The patient did well for 18 days with a functioning filter and intraocular pressure less than $10 \mathrm{mmHg}$, but with continued signs of moderate inflammation in the aqueous in spite of the reinstitution of topical dexamethasone phosphate $0 \cdot 1 \%$ every two hours.

Three weeks later the intraocular pressure had risen to $39 \mathrm{mmHg}$, with no visible conjunctival bleb and no response to ocular massage. While timolol $0.5 \%$ and atropine $0.1 \%$ drops were administered twice daily, intraocular pressure remained around 30 $\mathrm{mmHg}$. Because of progressive changes in nerve head and visual field a Molteno tube ${ }^{6}$ was inserted in the superotemporal aspect of the chamber angle on 20 October 1983. Intraocular pressures remained less

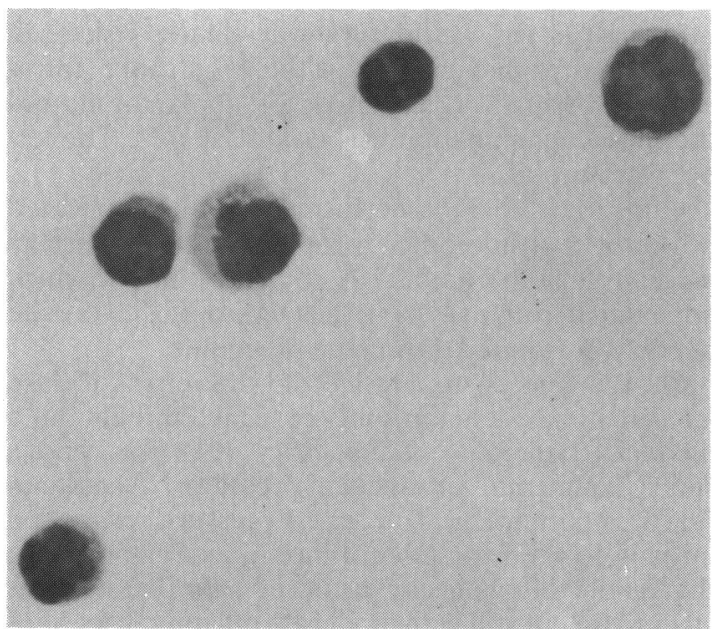

Fig. 1 Giemsa-stained mononuclear cells from anterior chamber aspirate. $(\times 437)$.
Table 1 Comparison of lymphocyte surface antigens found in anterior chamber and peripheral blood

\begin{tabular}{lll}
\hline Antibody specificity & \multicolumn{2}{l}{$\%$ Positive cells } \\
\cline { 2 - 3 } & $\begin{array}{l}\text { Anterior } \\
\text { chamber }\end{array}$ & $\begin{array}{l}\text { Peripheral } \\
\text { blood }\end{array}$ \\
\hline pan T & 100 & 67 \\
Ia & 8 & 19 \\
$\mathrm{~T}_{8}$ & 1 & 24 \\
\hline
\end{tabular}

than $10 \mathrm{mmHg}$ until three weeks postoperatively, at which time the intraocular pressure was $40 \mathrm{mmHg}$, and the tube could no longer be visualised in the chamber angle.

Further surgery was deferred at the patient's request. The intraocular pressure persisted at around $40 \mathrm{mmHg}$ while on timolol and atropine, and only a small temporal island of visual field remained with total cupping of the optic nerve head.

\section{RESULTS OF ANTERIOR CHAMBER PARACENTESIS}

A small volume of anterior chamber aspirate $(0 \cdot 15$ $\mathrm{ml}$ ) was placed in heparinised tissue culture medium and transported to the laboratory for Giemsa cytology and immunoperoxidase staining. ${ }^{7}$ Examination of the Giemsa-stained slide revealed predominantly mononuclear cells consisting of $0 \%$ neutrophils, $24 \%$ monocytes, $75 \%$ lymphocytes, and $1 \%$ immature lymphocytes (Fig. 1). Immunoperoxidase staining disclosed that $100 \%$ of the lymphocytes were positive for a pan $\mathrm{T}$ cell marker; $8 \%$ were Ia antigen positive and only $1 \%$ were $\mathrm{T}-8$ antigen positive (Fig. 2, Table 1).

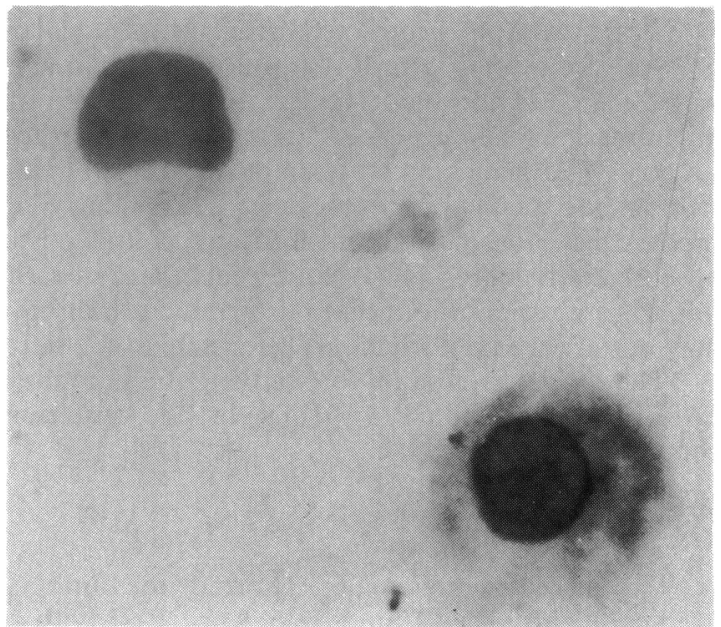

Fig. 2 Immunoperoxidase staining for Ia antigen. Cell at lower right is Ia antigen positive. $(\times 1165)$. 


\section{Discussion}

The reasons for the postoperative intraocular inflammation and raised intraocular pressure in this patient are unclear. The differential diagnosis for the anterior segment inflammation included either a response to sequestered lens material released at the time of capsulotomy, or early postoperative endophthalmitis, or an exacerbation of the inflammatory signs that are a part of Fuchs's syndrome. We found the anterior chamber paracentesis valuable in that the primarily lymphocytic response made the first two possibilities unlikely. The cytological features in this patient are consistent with those described in Fuchs's syndrome by others ${ }^{8-11}$ in that the aqueous of patients with Fuchs's syndrome contains numerous inflammatory cells, primarily of the mononuclear series.

Glaucoma, which proved relentless and devastating in this eye, is reported to occur in from 0 to $56 \%$ (average 15\%) of eyes with Fuchs's heterochromic cyclitis $^{12}$ and represents the most serious complication of the syndrome.

Acute increases of intraocular pressure associated with cataract extraction in eyes with this disease have been reported. ${ }^{3413}$ Moreover, an increased pressure following paracentesis was even considered a provocative test for glaucoma in heterochromic cyclitis. ${ }^{5}$

The glaucoma in eyes with Fuchs's syndrome is believed to be due to high outflow resistance caused by trabecular sclerosis. $\mathrm{A}$ postoperative rise in intraocular pressure such as that seen in the present case may be due to further embarrassment of already compromised outflow channels by increased numbers of chronic inflammatory cells. We doubt whether the glaucoma was related to steroid responsiveness because the intraocular pressure remained raised for nearly four months after discontinuation of topical dexamethasone prior to trabeculectomy.

The glaucoma associated with Fuchs's syndrome is said to be permanent and generally refractory to medical management but amenable to trephining procedures. ${ }^{14}$ Unfortunately our case proved to be resistant to both medical and surgical management, perhaps not surprisingly in the face of continuing inflammation.

Although many authors offer a variety of opinions on the prognosis for intraocular surgery in eyes with Fuchs's heterochromic cyclitis, our case would support the contention that such eyes have potential for developing increased inflammatory signs and glaucoma following intraocular manipulation. Our experience also underscores the notion that glaucoma is the most serious complication in this syndrome and that it can be refractory to successful medical and surgical intervention.

Immunoperoxidase staining is an appropriate way of determining the phenotype of inflammatory cells in anterior chamber fluid. It is more sensitive than immunofluorescence and has the added advantage of providing a permanent staining reaction. The technique can be used on the small number of cells retrievable from the anterior chamber. Whether it is useful to determine the phenotypes of cells in anterior uveitis is under investigation.

Grateful acknowledgement is made to Keryn Williams, Marion Roberts, Julie Ash, and Heddi Zola for their assistance in preparing this paper.

\section{References}

1 Franceschetti A. Heterochromic cyclitis'(Fuchs' syndrome). Am J Ophthalmol 1955; 39: 50-8.

2 Smith RE, O'Connor R. Cataract extraction in Fuchs sydrome. Arch Ophthalmol 1974; 91: 39-41.

3 Ward DM, Hart CT. Complicated cataract extraction in Fuchs's heterochromic uveitis. Br J Ophthalmol 1967; 51: 530-8.

4 Norn MS. Cataract extraction in Fuchs' heterochromia. Acta Ophthalmol (Kbh) 1968; 46: 685-99.

5 Huber A. Das Glaukom bei komplizierter. Heterochromie Fuchs. Ophthalmologica 1961; 141: 122-35; 142: 66-115.

6 Ancker E, Molteno ACB. Molteno drainage implant for neovascular glaucoma. Trans Ophthalmol Soc UK 1982; 102: 122-4.

7 Hancock WW, Becker GJ, Atkins RC. A comparison of fixatives and immunohistochemical techniques for use with monoclonal antibodies to cell surface antigens. Am J Clin Pathol 1982; 78: 825 .

8 Goldberg MF, Erozan YS, Duke JR, Frost JK. Cytopathologic and histopathologic aspects of Fuchs's heterochromic iridocyclitis. Arch Ophthalmol 1965; 74: 604-9.

9 Matteucci M. Considérations pathogéniques sur l'hétérochromie de Fuchs. Bull Mem Soc Fr Ophtalmol 1950; 63: 220-4.

10 Matteucci M. Considérations pathogéniques sur l'hétérochromie irienne de Fuchs. Ann Oculist (Paris) 1951; 184: 383-403.

11 Verray F. Hétérochromies de l'iris. In: Clinique de l'humeur aqueuse pathologique. Neuchatel and Paris: Delachaux and Niestlé, 1954: 214-8.

12 Lowenfeld IE, Thompson HS. Fuchs's heterochromic cyclitis: a critical review of the literature. I. Clinical characteristics of the syndrome. Surv Ophthalmol 1973; 17: 394-457.

13 Sym WG. Heterochromia iridum. Ophthalmol Rev 1889; 8: 202-5.

14 Grant WM. Heterochromic cyclitis (Fuchs). In: Chandler PA, Morton Grant W, eds. Glaucoma. Philadelphia: Lea and Febiger, 1979: 247-9. 